\title{
Klinoptilolit Dolgulu PVA Membranların Hazırlanması, Karakterizasyonu ve Pervaporasyon ile Desalinasyon Çalışmaları
}

\author{
Berk Tırnakçı $^{1}$, Yavuz Salt ${ }^{2 *}$, İnci Salt ${ }^{3}$, Seyfullah Keyf ${ }^{4}$ \\ ${ }^{1}$ Yıldız Teknik Üniversitesi, Kimya-Metalurji Fakültesi, Kimya Mühendisliği Bölümü, İstanbul, Türkiye (ORCID: 0000-0002-4391-6364) \\ ${ }^{2}$ Yıldız Teknik Üniversitesi, Kimya-Metalurji Fakültesi, Kimya Mühendisliği Bölümü, İstanbul, Türkiye (ORCID: 0000-0002-1375-6953) \\ ${ }^{3}$ Yıldız Teknik Üniversitesi, Kimya-Metalurji Fakültesi, Kimya Mühendisliği Bölümü, İstanbul, Türkiye (ORCID: 0000-0002-2702-5991) \\ ${ }^{4}$ Yıldız Teknik Üniversitesi, Kimya-Metalurji Fakültesi, Kimya Mühendisliği Bölümü, İstanbul, Türkiye (ORCID: 0000-0001-8846-0674)
}

(İlk Geliş Tarihi 2 Şubat 2020 ve Kabul Tarihi 20 Mart 2020)

(DOI: 10.31590/ejosat.682928)

ATIF/REFERENCE: Tırnakçı, B. Salt, Y., Salt, İ. \& Keyf, S. (2020). Klinoptilolit Dolgulu PVA Membranların Hazırlanması, Karakterizasyonu ve Pervaporasyon ile Desalinasyon Çalışmaları. Avrupa Bilim ve Teknoloji Dergisi, (18), 711-718.

$\ddot{O} z$

Membran prosesleri; son yıllarda birçok alanda kendine uygulama alanı bulduğu gibi, tuzlu sudan temiz su eldesine dair çalı̧̧malarda da dikkatleri üzerine çekmektedir. Desalinasyon uygulamalarında büyük oranda termal işlemler kullanılmaktadır. Bununla beraber membran uygulamaları su kitlığının önüne geçebilmek amacıyla büyük önem kazanmaktadır. Membran prosesleri arasında pervaporasyon (yarı seçici buharlaşma), desalinasyona yönelik olarak büyük potansiyele sahiptir ve yoğun membranlar kullanılarak sıvı karışımları ayırmak için kullanılan bir membran prosesidir. Poli(vinilalkol) (PVA) mühendislik uygulamalarında yaygın olarak kullanılan toksik olmayan, suda çözünebilir, biyobozunur, yarı kristalin sentetik bir polimerdir ve pervaporasyon desalinasyon çalışmalarında yüksek performanslı membranların hazırlanmasında yüksek hidrofilitesinden dolayı önemli bir seçenektir. Membranlar genellikle üç ana kategoriye göre sınıflandırılabilir: organik membranlar, inorganik membranlar ve kompozit membranlar. Polimerik matrislere zeolit gibi inorganik malzeme dolgulamaları ile kompozit karışı matrisli membranların (MMM) hazırlanması mümkündür ve bu sayede membran polimer matris ile inorganik dolgu malzemesinin olumlu yönleri polimer membranın fiziksel, kimyasal ve termal özelliklerini iyileştirmek amacıyla tek bir yapıda birleştirilebilir.

Bu çalışma kapsamında dolgusuz ve klinoptilolit dolgulanmış (ağırlıkça \%10) çapraz bağlı PVA kompozit membranlar çözelti-döküm tekniği kullanılarak hazırlanmıştır. Hazırlanan membranların farklı sıcaklıklarda $\left(30,40,50^{\circ} \mathrm{C}\right)$ saf su sorpsiyonları belirlenmiş ve pervaporasyon ile desalinasyon çalışmaları $30^{\circ} \mathrm{C}$ sıcaklıkta $35 \mathrm{~g} / \mathrm{L} \mathrm{NaCl}$ içeren sentetik deniz suyu kullanılarak gerçekleştirilmiştir. Hazırlanan membranlar; taramalı elektron mikroskobu (SEM), Fourier dönüşümlü kızılötesi spektroskopisi (FT-IR), termogravimetrik analiz (TGA) yöntemleriyle karakterize edilmiştir. Dolgusuz PVA ve klinoptilolit dolgulu PVA membranlar için sırasıyla; 1,1712 $\mathrm{kg} / \mathrm{m}^{2} \mathrm{~h}$ ve $0,8271 \mathrm{~kg} / \mathrm{m}^{2} \mathrm{~h}$ akı ve permeat numunelerinin iletkenlikleri ölçülerek $\% 99,83$ ve $\% 99,89$ tuz alıkoyma değerleri elde edilmiştir. Hazırlanan membranların desalinasyon uygulamalarında umut verici özelliklere sahip olduğu ortaya konmuştur.

Anahtar Kelimeler: Pervaporasyon, poli(vinilalkol), klinoptilolit, desalinasyon.

\section{Preparation and characterization of clinoptilolite incorporated PVA membranes and desalination with pervaporation studies}

\begin{abstract}
In recent years, membrane processes has found itself a wide practice area for many applications and has been promising for the treatment of saline water sources. Desalination applications are usually performed with thermal processes. However, membrane applications are gaining importance in order to prevent water scarcity. Pervaporation has great potential among membrane processes for desalination. Pervaporation (permselective evaporation) is a membrane process used to separate the liquid mixtures by using dense
\end{abstract}

\footnotetext{
* Sorumlu Yazar: Yıldız Teknik Üniversitesi, Kimya-Metalürji Fakültesi, Kimya Mühendisliği Bölümü, İstanbul, Türkiye, ORCID: 0000-0002-13756953, salt@yildiz.edu.tr
} 
membranes. Poly(vinylalcohol) (PVA) is a non-toxic, water-soluble, bio-degradable and semi crystalline synthetic polymer used in a wide of engineering applications, and it is an important option due to its hydrophilicity for the preparation of high-performance membranes in pervaporation desalination studies. Membranes can be classified into three main category: organic membranes, inorganic membranes and composite membranes. It is possible to prepare mixed matrix membranes (MMM) with inorganic material incorporation such as zeolite into polymeric matrices, so that the advantages of polymer matrix and inorganic filler can be combined in a single structure to improve the physical, chemical and thermal properties.

In this study, cross-linked unfilled PVA and clinoptilolite-filled PVA (10\% wt.) composite membranes were prepared using solutioncasting method. Pure water sorptions in the prepared membranes at different temperatures $\left(30,40,50^{\circ} \mathrm{C}\right)$ were determined and pervaporation desalination experiments were carried out using synthetic sea water $(35 \mathrm{~g} / \mathrm{L})$ at $30^{\circ} \mathrm{C}$. Membranes were characterized by scanning electron microscopy (SEM), thermogravimetric analysis (TGA), Fourier transform infrared spectroscopy (FT-IR). Fluxes of $1,1712 \mathrm{~kg} / \mathrm{m}^{2} \mathrm{~h}$ and $0,8271 \mathrm{~kg} / \mathrm{m}^{2} \mathrm{~h}$ for unfilled PVA and clinoptilolite-filled PVA membranes were obtained, respectively, and also salt rejection values of $99,83 \%$ and $99,89 \%$ were determined by measuring conductivity of permeate samples. Unfilled PVA and clinoptilolite-filled PVA membranes had promising properties in desalination applications.

Keywords: Pervaporation, poly(vinyl alcohol), clinoptilolite, desalination.

\section{Giriş}

Dünyada yaşamın temel kaynağı olan su, 21. yüzyılın en büyük problemlerinden biri haline gelmiştir. Hızla artan nüfus, kontrolsüz endüstrileşme ve iklim değişiklikleri içilebilir ve kullanılabilir su kaynaklarının hızla tükenmesine sebep olmaktadır. Özellikle su fakiri olan bir ülke olan Türkiye'de 2040 yılı projeksiyonları incelendiğinde, ciddi temiz su sorunları yaşanacağı görülmektedir (Ahmed ve ark., 2019). Bu su krizinin etkilerinin azaltılabilmesi amacıyla, sürdürülebilir su teknolojilerinin geliştirilmesi zorunlu hale gelmiştir.

Dünya yüzeyinin büyük bir bölümünü tuzlu suların oluşturması, bu kaynakların temiz su eldesi amacıyla kullanımı doğrultusunda dikkat çekmektedir. Tuzlu suyun özelliklerinin çeşitli teknolojilerle istenen özelliklere getirilmesi "desalinasyon" olarak adlandırılır. Günümüzde desalinasyon çalışmaları genellikle 1sıl işlemler olan çok aşamalı ani distilasyon (MSF) ve çok işlemli distilasyon (MED) ile bir membran prosesi olan ters osmoz (RO) ile gerçekleştirilmektedir (Humplik ve ark., 2011).

Desalinasyon uygulamalarında membran proseslerinin; yüksek ayırma performansı, enerji tasarrufu, endüstriyel sistemlere kolay entegrasyon gibi avantajları mevcuttur ve bu membran prosesleri arasında pervaporasyon önemli bir konumdadır (Drioli ve ark., 2011). Pervaporasyon (PV) yoğun yapılı membranların kullanıldığı, permeasyon ve evaporasyon adımları ile ayırmanın gerçekleştirildiği bir membran prosesidir. PV; basınç sürücülü olmayan ayırma mekanizması, sağladığı enerji tasarrufu, kirliliklere karşı dayanıklı olması, akı ve tuz alıkoyma oranları göz önüne alındığında yüksek ayırma performansına sahip olması ile desalinasyon uygulamalarında önemli bir alternatif olarak karşımıza çıkmaktadır (Wang ve ark., 2016).

Pervaporasyonda ayırmanın gerçekleştirilebilmesi için gerekli olan itici kuvvet, bileşenlerin kısmi basınçları arasındaki farktır ve bu fark genellikle bir vakum yardımı ile sağlanır (Huang, 1991). PV'nin ayırma mekanizması çözünme-difüzyon modeli ile açıklanır. Çözünme-difüzyon modeline göre membran üzerinden taşınım üç adımda gerçekleşir: (i) beslemenin membran tarafindan sorpsiyonu, (ii) bileşenlerin membran üzerinden difüzyonu, (iii) membranın diğer tarafından buhar faza desorpsiyonu (Noble \& Stern, 1995). Çözünme-difüzyon modelinin şematik gösterimi Şekil 1'de verilmektedir.

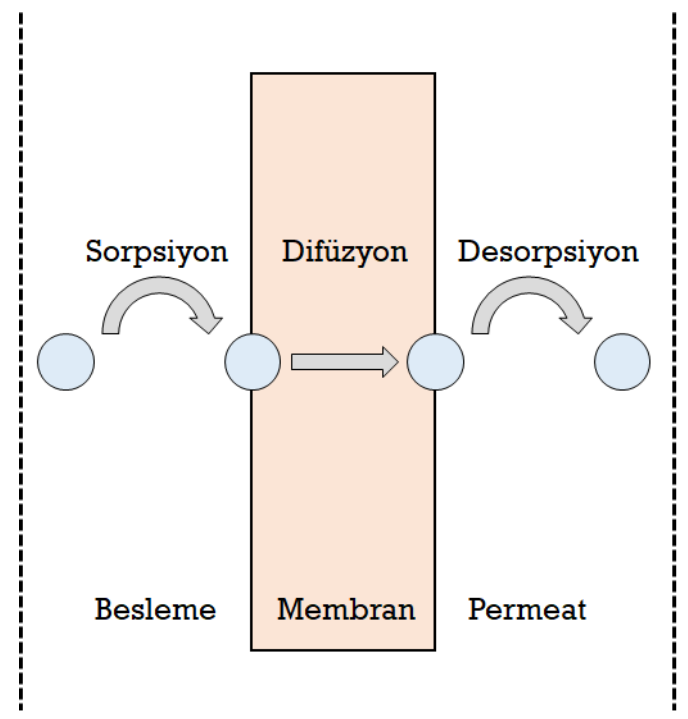

Şekil 1. Çözünme-Difüzyon modeli (Noble \& Stern, 1995).

Pervaporasyon ile desalinasyon uygulamalarında; tuzlu su ayırma hücresine beslenir, membran tuzun geçmesini engellerken, su membran boyunca taşınır ve temiz su eldesi sağlanır. Bu noktada yüksek ayırma performansına sahip membranların hazırlanması için hidrofilik yapıya sahip malzemelerin seçilmesi büyük önem taşımaktadır. Polivinil alkol (PVA), yapısında bulundurduğu hidroksil (- 
$\mathrm{OH})$ gruplarının sağladığı güçlü hidrofilik yapısı dışında; kolay ulaşılabilir ve işlenebilir olması, yüksek termal, mekanik ve kimyasal dayanıma sahip olması, toksik etki göstermemesi ve biyobozunur olması özellikleri ile PV ile desalinasyon uygulamalarında tercih edilebilecek önemli bir polimerik membran malzemesidir (Huang, 1991; Yilman ve ark., 2018).

Zeolitler üç boyutlu kristalin yapıda aluminosilikat minerallerdir (Dong ve ark., 2015) ve polimerik membran matrislerine dolgulandığında ayırma performanslarında artışlar sağladığı bilinmektedir (Kosinov ve ark., 2016). Genel formülü (Na, $\mathrm{K})_{6} \mathrm{Al}_{6} \mathrm{Si}_{30} \mathrm{O}_{72} \cdot 20 \mathrm{H}_{2} \mathrm{O}$ olan ve $\mathrm{Si} / \mathrm{Al}$ oranı 4 ila 5,3 arasında değişen klinoptilolit de zeolitler arasında; yüksek gözenekli ve sağlam yapısının yanında seçici difüzyon ve moleküler elek özellikleri ile ayırma işlemlerinde büyük avantajlara sahiptir ve bu avantajları sayesinde pervaporasyon ile desalinasyon çalışmalarında da yüksek potansiyele sahiptir (Kowalczyk ve ark., 2006; Koohsaryan \& Anbia, 2016).

An ve arkadaşları tarafından 2014 yılında yapılan çalışmada, klinoptilolit kullanılarak doğal zeolit membranlar hazırlanmış ve 25$95^{\circ} \mathrm{C}$ arasındaki sıcaklıklarda pervaporasyon ile desalinasyon çalışmaları gerçekleştirilmiştir. 1400 ppm tuzluluğa sahip besleme kullanılarak $95^{\circ} \mathrm{C}$ sıcaklıkta $15 \mathrm{~kg} / \mathrm{m}^{2} \mathrm{~h}$ su akısı ve \% 95'in üzerinde tuz alıkoyma değeri elde edilmiştir.

Swenson ve arkadaşları tarafindan yapılan bir diğer çalışmada (2012) ise klinoptilolit membranlar hazırlanarak pervaporasyon ile desalinasyon çalışmaları sentetik deniz suyu kullanılarak gerçekleştirilmiştir. Deneyler sonucu elde edilen veriler ile besleme bileşiminin membran performansına etkisi ortaya konmuştur. $93^{\circ} \mathrm{C}^{\prime}$ de yapılan performans analizleri sonucu, $100 \mathrm{mg} / \mathrm{L} \mathrm{Na}{ }^{+}$ve 5500 $\mathrm{mg} / \mathrm{L} \mathrm{Na}^{+}$besleme bileşimleri için sırasıyla $2,5 \mathrm{~kg} / \mathrm{m}^{2} \mathrm{~h}$ ve $0,39 \mathrm{~kg} / \mathrm{m}^{2} \mathrm{~h}$ akı ile $\% 95$ 'in üzerinde tuz alıkoyma değeri elde edilmiştir.

Bu çalışma kapsamında dolgusuz ve klinoptilolit dolgulu PVA membranlar çözelti-döküm yöntemi ile hazırlanarak sorpsiyon ve PV ile desalinasyon çalışmaları gerçekleştirilmiştir. Hazırlanan membranların saf su sorpsiyon davranışlarının sıcaklık ile ilişkisi incelenmiş dolgusuz ve klinoptilolit dolgulu PVA membranların pervaporasyon desalinasyon performansı dolgusuz PVA membranlar ile karşılaştırılmıştır. PV ile desalinasyon çalışmaları $35 \mathrm{~g} / \mathrm{L} \mathrm{NaCl}$ bileşiminde sentetik deniz suyu ile farklı sıcaklıklarda gerçekleştirilmiştir. Membranların karakterizasyonu SEM, TGA ve FT-IR ile yapılmıştır.

\section{Materyal ve Metot}

\subsection{Materyal}

Çalışma kapsamında kullanılan Fluka'dan temin edilen PVA \%99 hidroliz derecesine ve 72 kg/mol molekül ağırlığına sahiptir. Klinoptilolit, Manisa-Gördes bölgesinden elde edilen doğal zeolittir. PVA membran hazırlanırken çapraz bağlayıcı olarak tartarik asit $\left(\mathrm{C}_{4} \mathrm{H}_{6} \mathrm{O}_{6}\right)$ kullanılmıştır ve Merck'den temin edilmiştir. $35 \mathrm{~g} / \mathrm{L} \mathrm{NaCl}$ sentetik deniz suyu, laboratuvarda hazırlanmış olup, $\mathrm{NaCl}$ Merck'den temin edilmiştir.

\subsection{Membranların Hazırlanması}

Bu çalışmada, membranların hazırlanmasında çözelti-döküm yöntemi kullanılmıştır. İlk olarak \%10’luk PVA çözeltisi, saf su içerisinde $90^{\circ} \mathrm{C}$ 'de 3 saat karıştırılmıştır. Bu karıştırma işlemi esnasında karışım içerisine belirlenen miktarda klinoptilolit eklenerek homojen bir şekilde dağıtılmıştır. Daha sonra karışıma belirlenen oranda hazırlanmış \%10’luk tartarik asit çözeltisi eklenmiş ve karışım ultrasonik su banyosunda oda sıcaklığında belirli bir süre tutularak, karışma esnasında oluşan hava kabarcıklarının uzaklaştırılması sağlanmıştır. Hazırlanan karışım cam plakalara dökülerek, $40^{\circ} \mathrm{C}$ 'de 24 saat kurutulmuş, 24 saat sonunda plakalardan sıyrılarak alınmış ve $150^{\circ} \mathrm{C}$ 'de 1 saat boyunca çapraz bağlama işlemi gerçekleştirilmiştir. Membranlar, çapraz bağlama işlemi sonrasnda saf su içerisinde bir gün bekletilerek kalıntılar uzaklaştırılmış ve $105^{\circ} \mathrm{C}$ 'de 2 saat kurutulduktan sonra kullanıma hazır hale getirilmiştir.

\subsection{Karakterizasyon Çalışmaları}

\subsubsection{Taramalı elektron mikroskobu (SEM)}

Hazırlanan membranların kesit morfolojileri Carl Zeiss EVO LS 10 marka SEM cihazı ile 10 kV voltaj altında incelenmiştir. SEM analizlerinden önce membranlar sıvı azot içerisinde kırıldıktan sonra altın kaplanmıştır.

\subsubsection{Fourier dönüşümlü kızılötesi spektroskopisi (FT-IR)}

Membranların fonksiyonel kimyasal yapıları Perkin-Elmer Spectrum 100 FT-IR cihazı ile incelenmiştir. Çalışmalar $4000-650 \mathrm{~cm}^{-1}$ dalgaboyu aralığında gerçekleştirilmiştir.

\subsubsection{Fourier dönüşüm lü kızılötesi spektroskopisi (FT-IR)}

Dolgusuz ve dolgulu membranların termal özellikleri Exstar TG/DTA 6300 markalı cihaz ile azot atmosferinde, $10^{\circ} \mathrm{C} \mathrm{dk}^{-1} 1 \mathrm{sitma}$ hızında $25-800^{\circ} \mathrm{C}$ sıcaklık aralığında gerçekleştirilmiştir. 


\subsection{Sorpsiyon Çalışmaları}

PV'de ayırma; sorpsiyon, difüzyon ve desorpsiyon adımları ile gerçekleşmektedir. Bu nedenle sorpsiyon çalışmaları, pervaporasyon deneylerinde kullanılacak olan membranların, ilgili besleme bileşimleri ve çalışma sıcaklıklarındaki davranışlarına dair bilgiler sağlayabilmektedir. Sorpsiyon deneyleri gerçekleştirilirken şu adımlar izlenmektedir:

- Kuru tartımları alınan membranların ilgili sıvı içerisine daldırılması

- Sorpsiyon dengesine ulaşılana kadar, membranların belirli zaman aralıkları ile tartılarak ağırlık değişiminin takip edilmesi

- Sorpsiyon dengesine ulaşıldığında elde edilen veriler doğrultusunda sorpsiyon değerinin hesaplanması

Sorpsiyon dengesine ulaşıldıktan sonra toplam sorpsiyon değeri şu şekilde hesaplanır:

$$
\text { Sorpsiyon }(\%)=\left(\frac{W_{s}-W_{d}}{W_{d}}\right) \times 100
$$

Burada; $\mathrm{W}_{\mathrm{s}}$, sorpsiyon dengesine ulaşan membranın ağırlığını, $\mathrm{W}_{\mathrm{d}}$ ise kuru membran ağırlığını ifade etmektedir.

\subsection{Pervaporasyon Deneyleri}

Pervaporasyon ile desalinasyon çalışmaları şematik gösterimi Şekil 2'de verilen pervaporasyon sisteminde gerçekleştirilmiştir. (Salt ve ark., 2005; Salt ve ark., 2014).

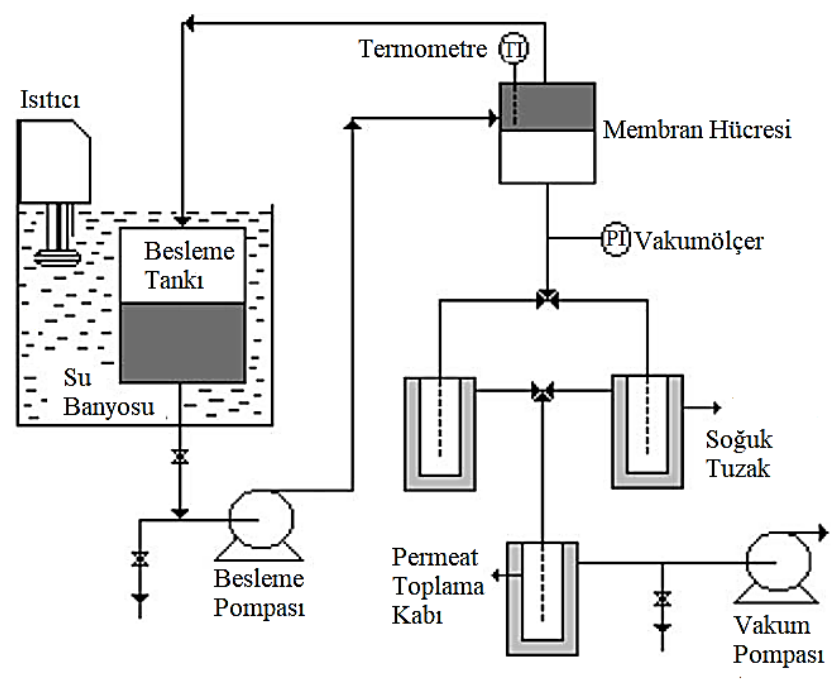

Şekil 2. Pervaporasyon sisteminin şematik gösterimi (Salt ve ark., 2005; Salt ve ark., 2014).

Pervaporasyon ile desalinasyon deneyleri 30,40 ve $50^{\circ} \mathrm{C}$ olmak üzere üç farklı sıcaklıkta gerçekleştirilmiştir. Besleme tankı bir su banyosu içerisinde sabit sıcaklıkta tutularak, besleme karışımı peristaltik pompa yardımıyla paslanmaz çelik membran hücresine beslenmiş̧tir. Membran hücresinde efektif membran alanı $23 \mathrm{~cm}^{2}$ dir. Vacuubrand RZ-5 marka vakum pompası yardımıla ayırmanın gerçekleştirilebilmesi için ihtiyaç duyulan $\leq 1 \mathrm{kPa}$ vakum oluşturulmuş ve Vacuubrand DVR-2 marka vakumölçer yardımıyla kontrol edilmiştir. Soğuk tuzaklar içerisindeki numune kaplarında toplanan permeat miktarı belirli aralıklarla tartılarak saf su akısı aşağıdaki formül ile hesaplanmıştır.

$$
J=\frac{W}{A \times t}
$$

Burada, $J$ saf su akısını $\left(\mathrm{kg} / \mathrm{m}^{2} \mathrm{~h}\right), w$ permeat ağılı̆̆ını $(\mathrm{kg}), A$ efektif membran alanını $\left(\mathrm{m}^{2}\right)$ ve $t$ zamanı (h) ifade etmektedir. Hazırlanan membranlar ile gerçekleştirilen, pervaporasyon ile desalinasyon çalışmaları sonucu elde edilen tuz alıkoyma değerleri ise iletkenlik testleri (İnoLab 730) ile belirlenmiştir ve şu şekilde hesaplanmıştır.

$$
R(\%)=\left[\frac{(C f-C p)}{C f}\right] \times 100
$$

Burada $R$ tuz alıkoyma değerini (\%), $C_{f}$ ve $C_{p}$ sırasıyla, beslemedeki ve permeattaki tuz konsantrasyonlarını (ppm) ifade etmektedir.

\section{Sonuçlar ve Tartışma}

\subsection{SEM Sonuçları}

Klinoptilolit dolgulu PVA membranların SEM analizi sonucu elde edilen görüntü Şekil 3’te verilmektedir. 


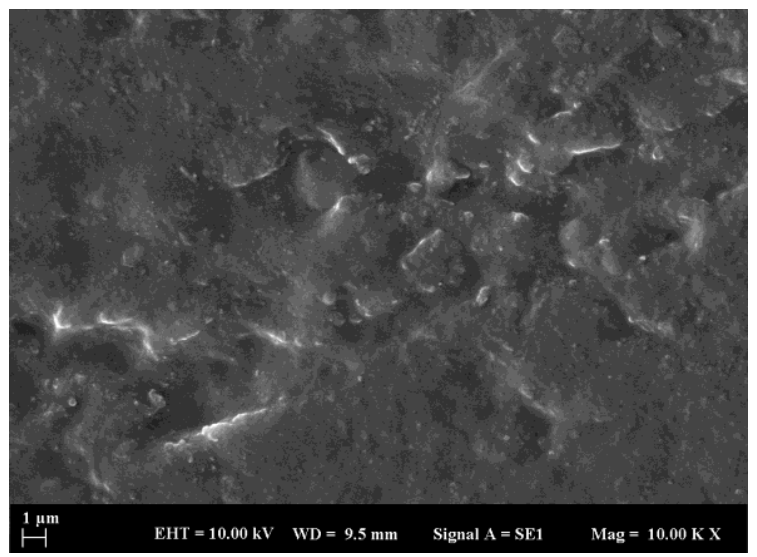

Şekil 3. Klinoptilolit dolgulu PVA membranın SEM görüntüsü.

Klinoptilolit dolgulu PVA membranın SEM görüntüleri klinoptilolitin, polimer matrise homojen bir şekilde dağılımının sağlandığını göstermektedir.

\subsection{FT-IR Sonuçları}

Dolgusuz ve klinoptilolit dolgulu PVA membranların FT-IR spektrumları Şekil 4'te gösterilmektedir. Elde edilen spektrumlarda her iki membran için 3000-3600 $\mathrm{cm}^{-1}$ dalgaboyları arasında görülmekte olan geniş bant, molekül içi ve moleküller arası hidrojen bağları sonucu ortaya çıkmış olan hidroksil grupları (-OH) gerilimi sonucu oluşmuştur. $2800-2900 \mathrm{~cm}^{-1}$ ve $1430 \mathrm{~cm}^{-1}$ dalgaboyları arasında ortaya çıkan titreşim bantları PVA'nın ana zincirinde bulunan -CH gerilmeleri sonucu oluşmuştur (Zhu ve ark., 2011). $1650-1710 \mathrm{~cm}^{-1}$ aralığındaki gerilme asetat gruplarından gelen $\mathrm{C}=\mathrm{O}$ ve $\mathrm{C}-\mathrm{O}$ titreşimlerinden kaynaklanmaktadır. $1000-1150 \mathrm{~cm}^{-1}$ arasındaki pikin yoğunluğu polimer zincirinin kristalin oranı ile belirlenmektedir. Bu pik simetrik $\mathrm{C}$-C gerilmesi sonucu ya da karbon zincirinin aynı tarafında bulunan komşu $\mathrm{OH}$ grupları arası moleküller içi hidrojen bağlarının oluşması sonucu ortaya çıktığı düşünülmektedir (Reis ve ark., 2006). Klinoptilolit dolgulaması ile spektrumda ortaya çıkmış gerilimlerin yoğunluğunun azaldığı görülmektedir.

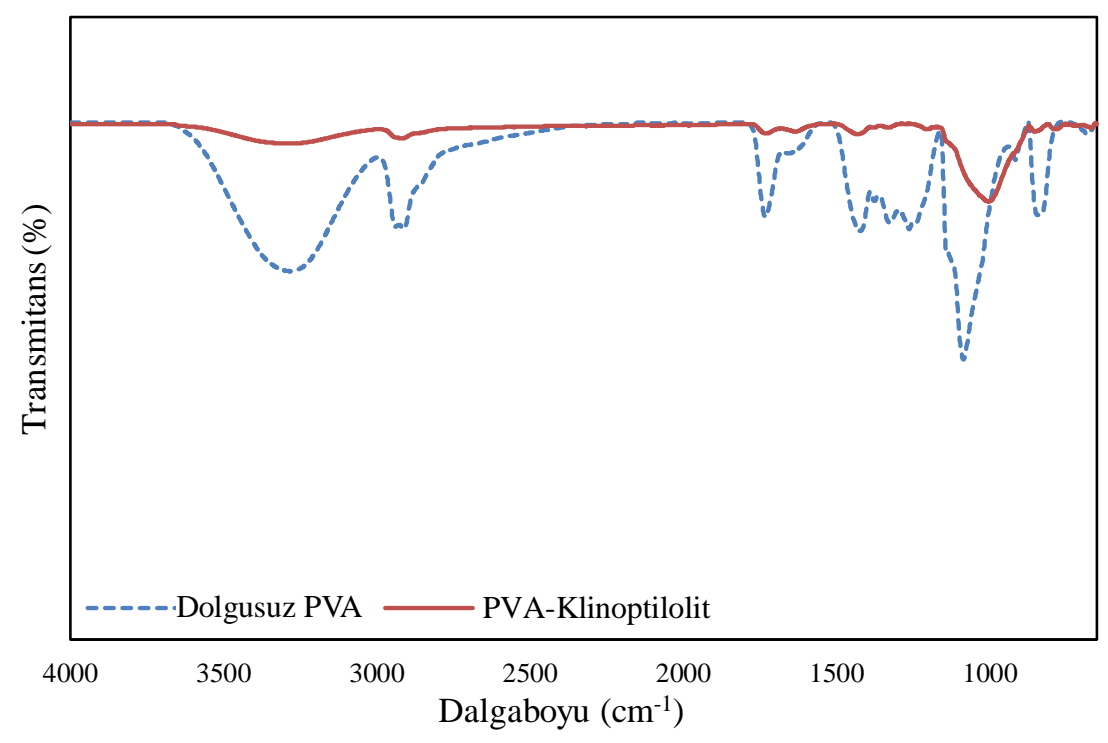

Şekil 4. Dolgusuz PVA ve klinoptilolit dolgulu PVA membranların FT-IR spektrumları.

\subsection{TGA Sonuçları}

Dolgusuz ve klinoptilolit dolgulu PVA membranların termogravimetrik analizleri sonucu elde edilen, 1sıl bozunma davranışları Şekil 5’te verilmiştir. Her iki membran için de kütle kaybının üç adımda gerçekleştiği görülmektedir. 


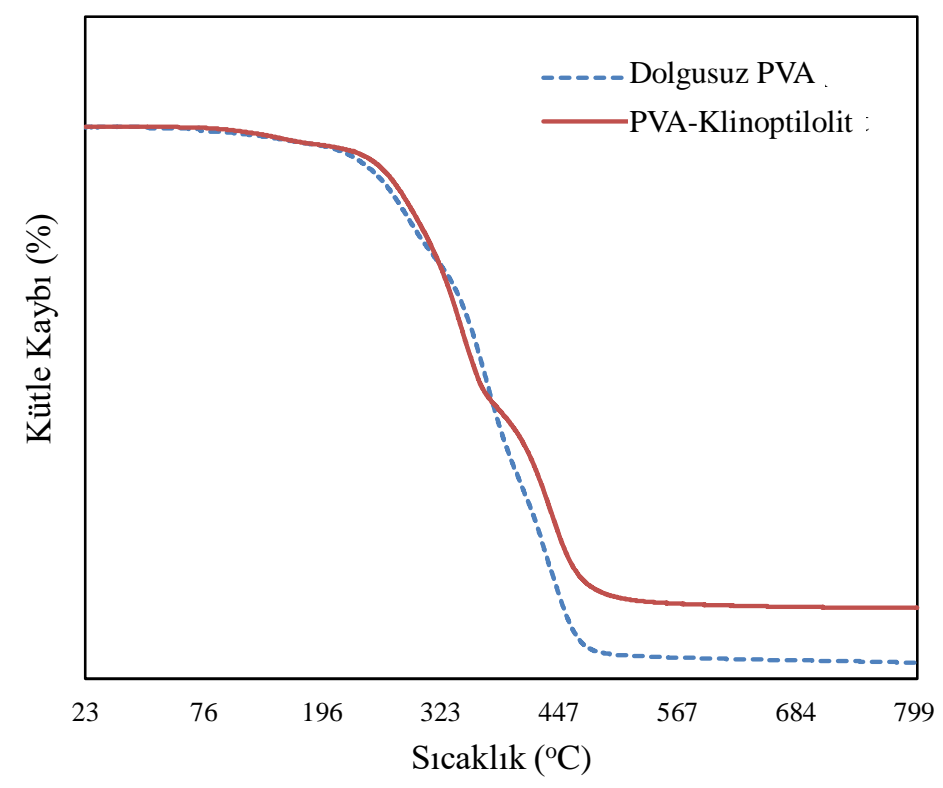

Şekil 5. Dolgusuz PVA ve klinoptilolit dolgulu PVA membranların termal analiz sonuçları.

Şekil 5'te verilen termal analiz sonucu incelendiğinde ilk kütle kaybı adımının $80-160^{\circ} \mathrm{C}$ arasında, yapıdaki suyun uzaklaşması sonucu ortaya çıktı̆̆ düşünülmektedir. PVA zincirinin bozunmasının, yaklaşık $250^{\circ} \mathrm{C}$ 'de ilk olarak, zincir üzerindeki yan grupların elimine edilmesi ile başladığı görülmektedir (Yang ve ark., 2011). Bu adımdaki kütle kaybı yaklaşı olarak $400^{\circ} \mathrm{C}$ 'de sona ermiştir. $\mathrm{Bu}$ adımı PVA ana zincirinin bozunmaya başladığı son kütle kaybı takip etmiş ve yaklaşık $500^{\circ} \mathrm{C}$ 'de bozunma süreci durmuştur (Yang ve ark., 2007). Hem PVA hem de PVA-Klinoptilolit membran için kütle kaybı profillerinin benzer olduğu görülmektedir. İki termogramın arasındaki temel fark kalıntı miktarlarıdır. Çalışılan sıcaklık aralığında klinoptilolitin inorganik yapısı bozunmayacağı için ortaya çıkan kalıntı miktarı, örneklerdeki yaklaşık klinoptilolit oranını vermektedir. Ayrıca klinoptilolit dolgusunun membranın termal dayanımını az da olsa arttırdığı görülmektedir.

\subsection{Sorpsiyon ve Pervaporasyon Deneyleri Sonuçları}

Hazırlanan dolgusuz ve klinoptilolit dolgulu PVA membranların sorpsiyon deneyleri 30,40 ve $50^{\circ} \mathrm{C}$ olmak üzere üç farklı sıcaklıkta, pervaporasyon çalışmaları ise $30^{\circ} \mathrm{C}^{\prime}$ de gerçekleştirilmiştir. Membranların saf su sorpsiyonlarının sıcaklık ile değişimi Şekil $6^{\prime}$ 'da gösterilmektedir. Sorpsiyon grafikleri incelendiğinde artan sıcaklık ile polimer segmental hareketlerinin artması sonucunda toplam sorpsiyon değerlerinin arttığı görülmektedir.

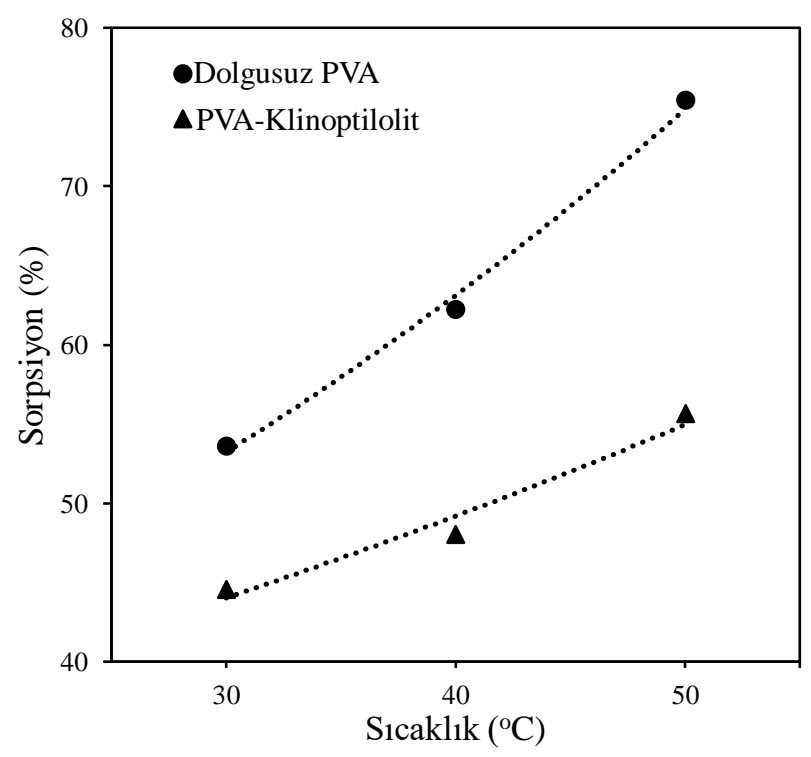

Şekil 6. Dolgusuz PVA ve klinoptilolit dolgulu PVA membranların saf su sorpsiyonlarının sıcaklık ile değişimi.

Dolgusuz ve klinoptilolit dolgulu PVA membranların $35 \mathrm{~g} / \mathrm{L} \mathrm{NaCl}$ içeren besleme karışımı ile $30^{\circ} \mathrm{C}$ 'de gerçekleştirilen deneyler sonucu elde edilmiş akı ve alıkoyma değerleri Şekil 7'de verilmektedir. 

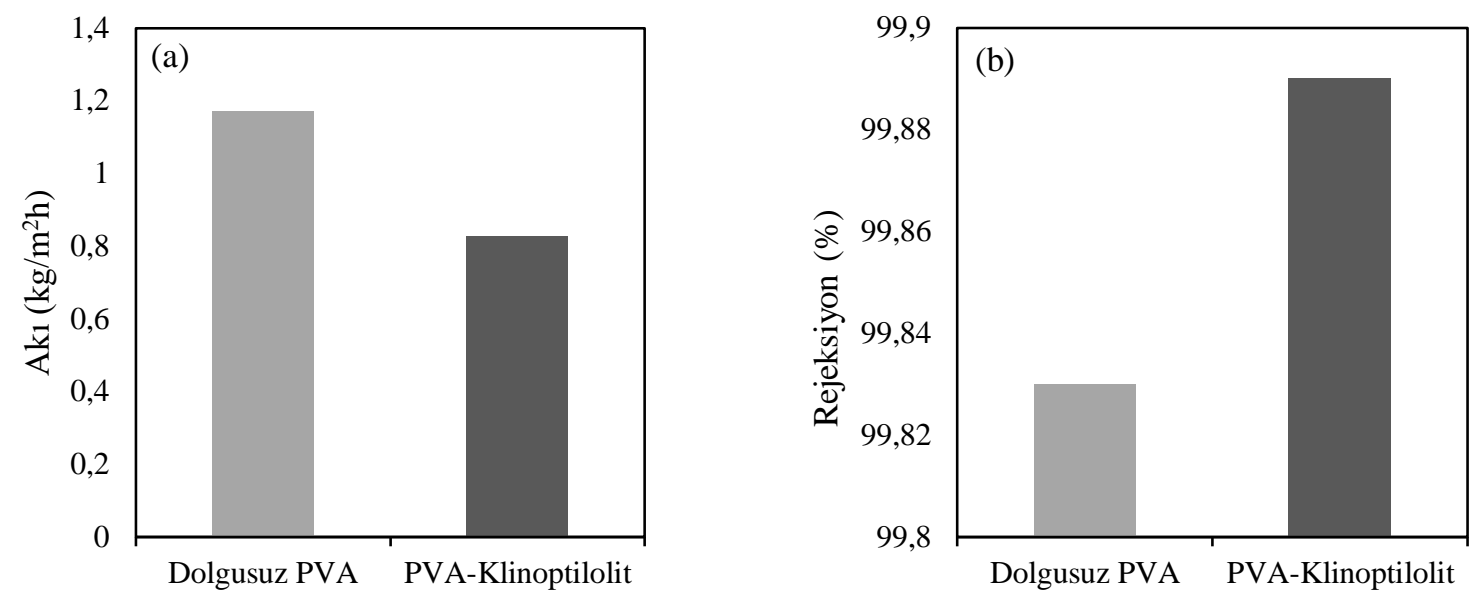

Şekil 7. Dolgusuz ve klinoptilolit dolgulu PVA membranlar için $30^{\circ} \mathrm{C}^{\prime}$ de akı (a) ve alıkoyma (b) değerleri.

Grafikte dolgusuz PVA ve klinoptilolit dolgulu PVA membran için akı ve alıkoyma değerleri sırasıyla; 1,$1712 ; 0,8271 \mathrm{~kg} / \mathrm{m}^{2} \mathrm{~h}$ ve $\% 99,83 ; \% 99,89$ olduğu görülmektedir. Veriler incelendiğinde \%10 oranında klinoptilolit dolgulamasının membran üzerinden su geçişini baskılayarak; akı değerlerinde düşüşe neden olduğu görülmektedir. Klinoptilolit içeren membranlar desalinasyon uygulamalarında göreceli olarak düşük akı değerlerine sahip olsa da; $\mathrm{Na}^{+}, \mathrm{Ca}^{2+}, \mathrm{Mg}^{2+}$ ve $\mathrm{K}^{+}$gibi katyonların giderilmesine yüksek potansiyele sahiptir (An ve ark., 2014). Bu durum, $30^{\circ} \mathrm{C}$ 'de gerçekleştirilen PV deneyleri sonucu elde edilen tuz alıkoyma değerleri ile de örtüşmektedir. Klinoptilolit dolgulaması ile tuz alıkoyma oranı \% 99,83’den yaklaşı olarak \% 99,89'a yükselmiştir.

\section{Sonuç}

Membran teknolojisi, birçok farklı alanda hızla ilerlemesinin yanında su arıtımı uygulamalarında da büyük umut vadetmektedir. Bu çalışma kapsamında klinoptilolit dolgulu PVA membranlar hazırlanarak farklı sıcaklıklarda sorpsiyon davranışları incelenmiş ve pervaporasyon ile desalinasyon uygulaması ile performans analizleri gerçekleştirilmiştir. Yapılan sorpsiyon çalışmaları sonucu artan sıcaklık ile her iki membran için de sorpsiyon değerlerinin arttığı ortaya konmuştur. Bununla beraber $30^{\circ} \mathrm{C}$ 'de, $35 \mathrm{~g} / \mathrm{L}$ besleme bileşiminde gerçekleştirilen pervaporasyon deneyleri sonucu, klinoptilolit dolgulaması ile su akısının düşüş gösterirken; tuz alıkoyma oranının zeolit dolgulaması ile daha yüksek değerlere ulaştı̆̆ı ortaya konmuştur. Çalışma kapsamında hazırlanıp, kullanılan membranların pervaporasyon ile desalinasyon uygulamalarında potansiyele sahip olduğu düşünülmektedir.

\section{Kaynakça}

Ahmed, F.E., Hashaikeh, R., \& Hilal, N. (2019). Solar powered desalination-Technology, energy and future outlook. Desalination, 453, 54-76.

An, W., Zhou, X., Liu, X., Chai, P.W., Kuznicki, T., \& Kuznicki, S.M. (2014). Natural zeolite clinoptilolite-phosphate composite Membranes for water desalination by pervaporation. Journal of Membrane Science, 470, 431-438.

Dong, J., Xu, Z., Yang, S., Murad, S., Hinkle, K.R. (2015). Zeolite membranes for ion separation from aqueous solutions. Current Opinion in Chemical Engineering, 8, 15-20.

Drioli, E., Stankiewicz, A.I., \& Macedonio F. (2011). Membrane engineering in process intensification-an overview. Journal of Membrane Science, 380, 1-8.

Huang R.Y.M. (1991). Pervaporation Membrane Separation Process, Amsterdam: Elsevier.

Humplik, T., Lee, J., O’Hern, S.C., Fellman, B.A., Baig, M.A., Hassan, S.F., Atieh, M.A., Rahman, F., Laoui, T., Karnik, R., \& Wang E.N. (2011). Nanostructured materials for water desalination. Nanotechnology, 22, 292001.

Koohsaryan, E., \& Anbia, M. (2016). Nanosized and hierarchical zeolites: A short review. Chinese Journal of Catalysis, 37, 447-467.

Kosinov, N., Gascon, J., Kapteijn, F., \& Hensen, E.J.M. (2016). Recent developments in zeolite membranes for gas separation. Journal of Membrane Science, 499, 65-79.

Kowalczyk, P., Sprynskyy, M., Terzyk, A.P., Lebedynets, M., Namiesnik, J., \& Buszewski, B. (2006). Porous structure of natural and modified clinoptilolites. Journal of Colloid and Interface Science, 297, 77-85.

Noble R. D., \& Stern S. A. (1995). Membrane Separations Technology, Principles and Applications. Amsterdam: Elsevier.

Reis, E.F., Campos, F.S., Lage, A.P., Leite, R.C., Heneine, L.G., Vasconcelos, W.L., Mansur, H.S. (2006). Synthesis and characterization of poly(vinyl alcohol) hydrogels and hybrids for rMPB70 protein adsorption. Materials Research, 9, 185-191.

Salt Y., Arçevik E., Ekinci B. (2014). Sorption and Pervaporation Results of Clinoptilolite Filled Poly(vinylalcohol) Membrane Prepared for Dehydration of Aqueous Organic Mixtures, The Canadian Journal of Chemical Engineering, 92(3), 503-510.

Salt, Y., Hasanoğlu, A., Salt, İ., Keleşer, S., Özkan, S., \& Dinçer, S. (2005). Pervaporation separation of ethylacetate-water mixtures through a crosslinked poly(vinylalcohol) membrane. Vacuum, 79, 215-220.

Swenson, B., Tanchuk, B., Gupta, A., An, W., \& Kuznicki, S.M. (2012). Pervaporative desalination of water using natural zeolite membranes. Desalination, 285, 68-72.

Wang, Q., Li, N., Bolto, B., Hoang, M., \& Xie Z. (2016). Desalination by Pervaporation-A review. Desalination, 387, 46-60. 
Yang C.-C. (2007). Synthesis and characterization of the cross-linked $\mathrm{PVA} / \mathrm{TiO}_{2}$ composite polymer membrane for alkaline DMFC. Journal of Membrane Science, 288, 51-60.

Yang C.-C., Li Y.J., \& Liou T.-H. (2011). Preparation of novel poly (vinyl alcohol)/SiO ${ }_{2}$ nanocomposite membranes by a sol-gel process and their application on alkaline DMFCs. Desalination, 276, 366-372.

Yilman, B., Nigiz, F.U., Aytaç, A., \& Hilmioglu, N.D. (2018). Multi-walled carbon nanotube doped PVA membrane for desalination. Water Supply, 19, 1229-1237.

Zhu, L., Wang, J., Guo, L., \& Shen J. (2011). Study on the preparation and properties of the $\mathrm{PVA} / \mathrm{SiO}_{2}$ hybrid coating on BOPP film via sol-gel process. Advanced Materials Research, 239-242, 1956-1959. 